\title{
Effects of in utero and Postnatal Exposure to Secondhand Smoke on Lung Function by Gender and Asthma Status: The Seven Northeastern Cities (SNEC) Study
}

\author{
Li-Wen Hu $^{a}$ Mo Yang ${ }^{b}$ Shu Chen ${ }^{c}$ Kuntal Shah ${ }^{d}$ Yismaw Hailegiorgis ${ }^{d}$ \\ Richai Burgens $^{d}$ Michael Vaughn $^{\mathrm{e}}$ Jin Huang ${ }^{\mathrm{e}}$ Pamela Xaverius $^{d}$ \\ Gunther Paul $^{f}$ Lidia Morawskag $^{9}$ Tao Lu ${ }^{\text {h }}$ Shao Lin ${ }^{\text {h }}$ Shou-Qiang Zhong ${ }^{i}$ \\ Min-Li Kong ${ }^{i}$ Yan-Qi Xie ${ }^{i}$ Yuan-Tao Hao ${ }^{j}$ Xiao-Wen Zeng $^{a} \quad$ Zhengmin Qian $^{d}$ \\ Guang-Hui Dong ${ }^{a}$
}

\begin{abstract}
${ }^{a}$ Guangzhou Key Laboratory of Environmental Pollution and Health Risk Assessment, Department of Preventive Medicine, School of Public Health, Sun Yat-sen University, Guangzhou, ${ }^{b}$ Key Laboratory of Chemical Safety and Health, National Institute for Occupational Health and Poison Control, Chinese Center for Disease Control and Prevention, and ${ }^{\mathrm{C} D e p a r t m e n t}$ of Thoracic Surgery, Fu Xing Hospital of Capital Medical University, Beijing, China; d Department of Epidemiology, College for Public Health and Social Justice, Saint Louis University, Saint Louis, MO, eSchool of Social Work, College for Public Health and Social Justice, Saint Louis University, Saint Louis, MO, USA; ${ }^{f}$ Faculty of Health, School of Public Health and Social Work, Queensland University of Technology, ${ }^{9}$ International Laboratory for Air Quality and Health (WHO CC for Air Quality and Health), Australia-China Centre for Air Quality Science and Management, Queensland University of Technology, Brisbane, QLD, Australia; ${ }^{\mathrm{h}}$ Department of Epidemiology and Biostatistics, School of Public Health, State University of New York, Albany, NY, USA; 'Department of Gynaecology and Obstetrics, Maternal and Child Health Hospital of Maoming City, Maoming, ${ }^{j}$ Department of Epidemiology and Biostatistics, School of Public Health, Sun Yat-sen University, Guangzhou, China
\end{abstract}

\section{Keywords}

Lung function · Secondhand smoke · Gender · Asthma · Interaction effect

\begin{abstract}
Background: Little information exists on whether gender or asthma status modifies the effects of secondhand smoke (SHS) exposure on lung function. Objective: To evaluate whether gender or asthma status modifies the association of SHS exposure with lung function. Methods: A total of 6,740 children (average 11.6 years) were recruited from 24 districts of 7 cities in northeast China in 2012. SHS exposure included
\end{abstract}

\section{KARGER}

(c) 2017 S. Karger AG, Basel

E-Mail karger@karger.com

www.karger.com/res exposure to environmental and maternal smoking both in utero and during early childhood (postnatal). Lung function was measured using electronic spirometers. Two-step regressions were used to analyze the association between SHS and lung function. Results: In utero and postnatal exposure to SHS was independently associated with decreased lung function in both genders; however, this association was greater among males. For example, when exposed to maternal smoking during pregnancy, the adjusted odds ratio (aOR)

Prof. Guang-Hui Dong

Guangzhou Key Laboratory of Environmental Pollution and Health Risk Assessment Department of Preventive Medicine, School of Public Health, Sun Yat-sen University 74 Zhongshan 2nd Road, Yuexiu District, Guangzhou 510080 (PR China) E-Mail donggh5@mail.sysu.edu.cn or donggh512@ hotmail.com

Prof. Zhengmin (Min) Qian

Department of Epidemiology, College for Public Health and Social Justice Saint Louis University, Salus Center/Room 473

3545 Lafayette Avenue, Saint Louis, MO 63104 (USA)

E-Mail zqian2@slu.edu 
for decreased forced vital capacity (FVC) was 6.46 (95\% confidence interval $[\mathrm{Cl}]: 2.58-16.17)$ among males, while only 2.16 (95\% Cl: 0.96-4.88) among females. More positive associations between SHS exposure and decreased lung function were detected among nonasthmatic compared with asthmatic children. Nonasthmatics had significantly larger deficits from in utero exposure to maternal smoking, which concerned decreased lung FVC function $(\mathrm{aOR}=2.58,95 \% \mathrm{Cl}$ : 1.28-5.21) and decreased lung forced expiratory volume in $1 \mathrm{~s}$ (FEV1) function $(\mathrm{aOR}=2.32,95 \% \mathrm{Cl}: 1.01-5.33)$. A similar pattern was also observed for the associations between SHS exposure and continuous pulmonary function test measurements. Conclusions: SHS exposure was associated with decreased lung function. Males and nonasthmatics seem to be more susceptible than their respective counterparts.

(c) 2017 S. Karger AG, Base

\section{Introduction}

Secondhand smoke (SHS), a highly prevalent respiratory irritant, consists of a complex mixture of more than 4,000 different chemicals [1]. Compared to adults, children are more vulnerable to SHS exposure because their respiratory and immune systems are not fully developed. An extensive body of evidence has shown that SHS exposure is associated with respiratory symptoms [2-6] and lung function [7-10] in children.

Although most studies consistently associate SHS exposure with deficits in lung function, others did not find significant effects of SHS exposure on lung function [11, 12]. Sherrill et al. [11] examined the longitudinal effects of smoke exposure on lung function in a cohort of New Zealand children observed from age 9 to 15 years. Results from this study showed no significant detrimental effects on absolute forced expiratory volume in $1 \mathrm{~s}$ (FEV1) and forced vital capacity (FVC) in either sex in the whole cohort. Another cohort study conducted in a population of nonsmoking Dutch children aged 6-12 years reported that lung function growth, measured over a period of 2 years, was not consistently associated with any indoor exposure variables, including SHS [12]. These inconsistencies in results may be due to the variation in the proportion of sensitive children in the study population [8]. Children with asthma are particularly sensitive to the effects of SHS exposure during the postnatal period, and are more prone to the acute effects of SHS compared to children without asthma [13]. Children with asthma who are exposed to maternal smoking in utero may have large deficits because the effects of in utero exposure on lung func- tion may add to the chronic deficits from asthma [14]. Although the combination of in utero and postnatal SHS exposure may be particularly important for children with asthma and may explain some of the inconsistencies among studies, the effects of in utero exposure by gender and asthma status have not been extensively investigated.

Additionally, some authors have indicated that the effect of exposure to environmental factors on deficits in lung function among different races was inconsistent [15]. A few of these studies are from China, where a large percentage of the population lives in crowded apartments. However, the proportion of female smokers (3\%) is very low in China, compared to other developed countries such as the US (22\%) and Denmark (40\%) [16-18]. Also, SHS exposure in China is almost entirely paternal (57\% of men smoke) [18]. Furthermore, in China, women that smoke are considered to be humiliating and are discriminated against according to conventional rules of etiquette, whereas smoking is a male symbol, and it is a common practice in China for men to engage in smoking indoors, inside the home, etc., which can lead to much higher levels of mother and child exposure to SHS. Therefore, we believed it was necessary to examine involuntary SHS exposure, especially from paternal smoking, on the health of school-aged children in China. In the present study, we investigated the associations between exposure to SHS and lung function among children, and whether asthma and gender modify these relationships.

\section{Methods}

Study City Selection and Subject Recruitment

Seven cities in the Liaoning province of China were selected to participate in a cross-sectional study known as the Seven Northeastern Cities (SNEC) study in April 2012. The study focused on children's health outcomes based on ambient air pollution measures between 2009 and 2012. Because there are over 20 million people in 14 cities of the Liaoning province, 7 cities were selected "to maximize the inter- and intra-city gradients of the pollutants of interest and also to minimize the correlation between districtspecific ambient pollutants" [19]. A total of 24 urban districts were selected from the 7 cities: 3 districts in Anshan, Benxi, and Dandong; 4 districts in Dalian and Fushun; 2 districts in Liaoyang; and 5 districts in Shenyang. For each district, there is 1 operative station that monitors the ambient air pollution and creates air pollution data. To generate a representative sample of all districts, random sampling was used to select 1 elementary and 1 middle school located within $1 \mathrm{~km}$ of the monitoring stations. Furthermore, for each selected school, only 1 or 2 classrooms per grade were targeted for inclusion in the sample. To participate, students had to have lived within a kilometer from the school and the monitoring station and within that district for at least 2 years prior to the start of the study. The procedures followed were in accordance with the 
ethical standards of the responsible committee on human experimentation of Sun Yat-sen University. All human experiments performed were approved by the Sun Yat-sen University Institutional Human Ethics Committee (Ethics Approval Number: 026) and were consistent with the Declaration Helsinki-Ethical Principles for Medical Research Involving Human Subjects. A written informed consent was obtained from the parent/guardian of each participant before data collection.

\section{Questionnaire Survey}

Consent from the principals of the participating schools was required prior to data collection. Next, teachers were provided with verbal and written instructions, questionnaires, envelopes, and forms to document distribution and collection of the questionnaires. The schools hosted an informative parents night about the study where they discussed the terms and conditions of being a participant. Teachers were directed to thoroughly inform the parents without any persuasion of filling out the questionnaire in order to ensure voluntary participation. Parents who consented to participate were offered the choice of filling out the questionnaire in the classroom or at home before having their child return it in a sealed envelope.

\section{Measures}

Exposure Variables

The SNEC questionnaire provided information on SHS exposure, and reported SHS exposure was classified into 4 different types: (a) any SHS exposure during maternal pregnancy (in utero) with the child; (b) mother ever actively smoking during pregnancy; (c) any SHS exposure during the first 2 years of children's lives; and (d) current household SHS exposure (further categorized into: mother smokes, father smokes, and other smoke). Smoking by visitors or guests was not ascertained. Current household smoke exposure was also measured in terms of how much cigarette smoke was present (categorized by $0,1-10$, or $>10$ cigarettes) during workdays and nonworkdays. All exposure variables were dichotomized as separate measures, including the subtypes of current SHS exposure.

\section{Outcome Variables}

The lung function testing and data management procedures used in the study have been reported previously [19]. FEV1, FVC, maximal mid-expiratory flow (MMEF), peak expiratory flow (PEF), and the FEV1 to FVC ratio (FEV1/FVC) were measured with 2 portable electronic type spirometers (Spirolab, MIR, Italy) by 2 experienced researchers and technicians. Pulmonary function testing was performed according to standardized protocols to measure continuous lung function values. The children were asked to stand comfortably and wear a nose clip to stop air from moving through the nose during the test. After the children were able to comprehend and follow these instructions, spirometry was performed using the ATS (American Thoracic Society) and ERS (European Respiratory Society) standards. The values of total lung capacity and residual volume were also reported. All measurements were corrected for body temperature and saturated pressure.

Measurements were performed in a quiet and comfortable room. Prior to taking any spirometric measurements, all study investigators and staff members successfully completed a training program that oriented them both to the specific tools and methodologies employed, as well as the aims of the study. At the training sessions, interviewers were given detailed instructions on how to administer the study questionnaire. All lung function observers participated in a special training session on the use of a standardized protocol for lung function measurement. After the completion of the training program, each successful trainee was required to pass a qualifying examination; those who were successful were given a lung function observer certificate. In addition, trainees were required to practice standard techniques for lung function measurement with an instructor and during a standardized videotaped examination.

Decreased lung function was defined as $\mathrm{FEV}_{1} \%<85 \%$ or $\mathrm{FVC}$ $<85 \%$, or $\mathrm{PEF}<75 \%$, or MMEF $<75 \%$ of the predicted value of the respective parameter [20]. These 4 outcomes were analyzed dichotomously as decreased or normal. All outcome variables were analyzed as separate measures.

\section{Covariates}

The following demographic and anthropometric covariates were adjusted for in each model to maintain consistency with the previous literature: age, gender, body mass index (BMI), breastfeeding, parental education level, family income per year, and the use of coal in the household. Gender and asthma status were tested as interaction variables to determine if they were effect modifiers.

Age was analyzed as a continuous variable. Breastfeeding was coded dichotomously based on whether the child was breastfed for $\geq 3$ months. Parental education was coded dichotomously based on whether the highest level of education of either parent was $\geq$ high school. Family income was a categorical variable in terms of the Chinese Yuan currency (RMB). Household coal use was a dichotomous variable defined by coal use for cooking or heating.

In order to determine the BMI of the study population, height and weight of all participants were measured using a standardized protocol from the World Health Organization - height measured to the nearest $0.5 \mathrm{~cm}$ and weight measured to the nearest $100 \mathrm{~g}$ using a lever balance. For height measurements, participants were asked to stand back against a wall, wearing no shoes, eyes looking straight forward and using a right-angle triangle placed on top of the head and against the wall. For weight measurements, participants stood on the scale without shoes and in only minimal undergarments. BMI was then calculated using the gathered weight data $(\mathrm{kg})$ and dividing it by height $(\mathrm{m})$ squared $\left(\mathrm{kg} / \mathrm{m}^{2}\right)$. Since our study population was comprised of preadolescent school children, we categorized BMI into age and sex-specific percentiles, based on the Centers for Disease Control and Prevention (CDC) BMI growth charts. According to the CDC standards, underweight is defined as BMI less than or equal to the 5 th percentile, overweight is defined as a "BMI greater than the age and sex-specific 85 th percentile," and obese as "BMI greater than the age and sex specific 95th percentile." For the purpose of standardized comparison, the BMI distribution was stratified by age and sex.

\section{Statistical Analysis}

Data were assessed for normality, using the Shapiro-Wilk W test, and homogeneity, with the Bartlett test for unequal variances, prior to statistical analysis. Means and standard deviations were calculated for age, and relative frequencies were calculated for all categorical variables. These values were stratified by both gender and asthma status. To determine the association between SHS exposure and dichotomized outcomes, we used contingency tables and $\chi^{2}$ tests. Two-step regression procedures were used to analyze 
Table 1. Characteristics of children in 24 districts by gender and asthma status

\begin{tabular}{|c|c|c|c|c|}
\hline \multirow[t]{2}{*}{ Variables } & \multicolumn{2}{|l|}{ Gender status } & \multicolumn{2}{|c|}{ Asthma status } \\
\hline & $\begin{array}{l}\text { males } \\
(n=3,382)\end{array}$ & $\begin{array}{l}\text { females } \\
(n=3,358)\end{array}$ & $\begin{array}{l}\text { yes } \\
(n=460)\end{array}$ & $\begin{array}{l}\text { no } \\
(n=6,280)\end{array}$ \\
\hline Age, years & $11.6 \pm 2.1$ & $11.5 \pm 2.0$ & $11.2 \pm 2.1$ & $11.6 \pm 2.1$ \\
\hline \multicolumn{5}{|l|}{ Body mass index category } \\
\hline Normal weight & $2,008(59.4)$ & $2,510(74.8)^{*}$ & $287(62.4)$ & $4,231(67.4)$ \\
\hline Overweight & $555(16.4)$ & $513(15.3)$ & $87(18.9)$ & $981(15.6)$ \\
\hline Obesity & $819(24.2)$ & $335(10.0)$ & $86(18.7)$ & $1,068(17.0)$ \\
\hline Breastfeeding & $2,312(68.4)$ & $2,439(72.6)^{*}$ & $300(65.2)$ & $4,451(70.9)$ \\
\hline Parental education $\geq$ higher school & $2,101(62.1)$ & $2,110(62.8)$ & $298(64.8)$ & $3,913(62.3)$ \\
\hline \multicolumn{5}{|l|}{ Family income per year, $\mathrm{RMB}^{\mathrm{a}}$} \\
\hline$\leq 5,000$ & $375(11.1)$ & $383(11.4)$ & $60(13.0)$ & $698(11.1)$ \\
\hline $5,000-10,000$ & $431(12.7)$ & $445(13.3)$ & $56(12.2)$ & $820(13.1)$ \\
\hline $10,000-30,000$ & $1,197(35.4)$ & $1,197(35.7)$ & $140(30.4)$ & $2,254(35.9)$ \\
\hline $30,000-100,000$ & $1,250(37.0)$ & $1,187(35.4)$ & $186(40.4)$ & $2,251(35.8)$ \\
\hline$>100,000$ & $129(3.8)$ & $146(4.4)$ & $18(3.9)$ & $257(4.1)$ \\
\hline Home coal use & $357(10.6)$ & $319(9.5)$ & $47(10.2)$ & $629(10.0)$ \\
\hline SHS exposure in utero & $608(18.0)$ & $696(20.7)^{*}$ & $122(26.5)$ & $1,182(18.8)^{*}$ \\
\hline Mother smoking during pregnancy & $20(0.6)$ & $34(1.0)$ & $11(2.4)$ & $43(0.7)^{*}$ \\
\hline SHS exposure in first 2 years of life & $660(19.5)$ & $738(22.0)^{*}$ & $125(27.2)$ & $1,273(20.3)^{*}$ \\
\hline \multicolumn{5}{|l|}{ Current SHS exposure } \\
\hline Father & $1,050(31.1)$ & $1,072(31.9)$ & $152(33.0)$ & $1,970(31.4)^{*}$ \\
\hline Mother & $300(8.9)$ & $308(9.2)$ & $57(12.4)$ & $551(8.8)$ \\
\hline Others & $273(8.1)$ & $278(8.3)$ & $43(9.4)$ & $508(8.1)$ \\
\hline Anyone & $1,623(48.0)$ & $1,658(49.4)$ & $252(54.8)$ & $3,029(48.2)^{*}$ \\
\hline \multicolumn{5}{|c|}{ Cigarettes smoked during workday, cigarettes/day } \\
\hline $1 \sim 10$ & $1,348(39.9)$ & $1,398(41.6)$ & $206(44.8)$ & $2,540(40.5)^{*}$ \\
\hline$\geq 10$ & $275(8.1)$ & $260(7.7)$ & $46(10.0)$ & $489(7.8)$ \\
\hline \multicolumn{5}{|c|}{ Cigarettes smoked during day off, cigarettes/day } \\
\hline $1 \sim 10$ & $1,319(39.0)$ & $1,370(40.8)$ & $202(43.9)$ & $2,487(39.6)^{*}$ \\
\hline$\geq 10$ & $304(9.0)$ & $288(8.6)$ & $50(10.9)$ & $542(8.6)$ \\
\hline \multicolumn{5}{|l|}{ Spirometric parameters } \\
\hline FVC, $\mathrm{L}$ & $2.8 \pm 0.8$ & $2.4 \pm 0.6^{*}$ & $2.5 \pm 0.8$ & $2.6 \pm 0.8^{*}$ \\
\hline FEV1, L & $2.6 \pm 0.8$ & $2.3 \pm 0.6^{*}$ & $2.3 \pm 0.7$ & $2.5 \pm 0.7^{*}$ \\
\hline $\mathrm{PEF}, \mathrm{L} / \mathrm{s}$ & $5.2 \pm 1.5$ & $4.4 \pm 1.2^{*}$ & $4.5 \pm 1.0$ & $4.8 \pm 1.4^{*}$ \\
\hline MMEF, L/s & $3.5 \pm 1.2$ & $3.2 \pm 0.9^{*}$ & $3.1 \pm 1.0$ & $3.4 \pm 1.1^{*}$ \\
\hline FEV1/FVC & $0.94 \pm 0.08$ & $0.95 \pm 0.07^{*}$ & $0.94 \pm 0.08$ & $0.92 \pm 0.08^{*}$ \\
\hline \multicolumn{5}{|l|}{ Lung function status } \\
\hline FVC $<85 \%$ predicted & $350(10.4)$ & $409(12.2)^{*}$ & $63(13.7)$ & $696(11.1)$ \\
\hline FEV $1<85 \%$ predicted & $303(9.0)$ & $275(8.2)$ & $52(11.3)$ & $526(8.4)^{*}$ \\
\hline $\mathrm{PEF}<75 \%$ predicted & $186(5.5)$ & $272(8.1)^{*}$ & $36(7.8)$ & $422(6.7)$ \\
\hline MMEF $<75 \%$ predicted & $287(8.5)$ & $347(10.3)^{*}$ & $66(14.4)$ & $568(9.0)^{*}$ \\
\hline
\end{tabular}

Values are presented as $\mathrm{n}(\%)$ or mean $\pm \mathrm{SD} .{ }^{*}$ The difference between males and females or between asthmatics and nonasthmatics is significant at the 0.05 level. ${ }^{a}$ Chinese Yuan.

the associations. Further details of these procedures can be found in a paper by Peters et al. [15]. Statistical analyses were conducted in SAS 9.4 (SAS Institute Inc., Cary, NC, USA), specifically with the use of the GLIMMIX model and a 2-sided test at an a-level of 0.05 . A full description of statistical analyses is provided in online supplementary material (for all online suppl. material, see www. karger.com/doi/10.1159/000455140).

\section{Results}

There were a total of 7,326 children randomly recruited from the 24 elementary schools and 24 middle schools, of which 7,109 completed the lung function measurement and returned the questionnaires, resulting in an 
overall response rate of $96 \%$. We further excluded 279 children (4\%) with a $<2$-year residence history in their district. In the final sample of 6,740 children, the average age was 11.6 years (standard deviation $=2.1$ years; ranging from 6.2 to 16.9 ), and 3,382 were males. The characteristics of the study participants in this study, stratified by gender and asthma, are shown in Table 1. Females, compared to males, had slightly higher percentages of all SHS exposure variables. Compared to nonasthmatic children, asthmatic children had higher percentages of all SHS exposure variables.

The mean levels of lung function were higher in the children without any exposure to SHS (in utero or later in life) compared to the exposed children. When stratified by gender and asthma status, the effects of in utero and postnatal SHS exposure were much larger in females and asthmatics than their counterparts, respectively (online suppl. material Table S4-S7).

Two-staged binary logistic regression modeling was conducted to calculate adjusted odds ratios (aOR) and 95\% confidence intervals (95\% CI) to examine the association of SHS exposure and lung function impairment (Table 2). As shown in Table 2, gender was an effect modifier on the relationship between decreased lung function and SHS exposure, with a larger effect on males than females. For example, when exposed to maternal smoking during pregnancy, the aOR for decreased FVC was 6.46 (95\% CI: $2.58-16.17$ ) in males, but was only 2.16 (95\% CI: $0.96-4.88$ ) in females. There was also a significant interaction between gender and SHS exposure for decreased FEV1 ( $\mathrm{p}<0.05)$. When stratified by the asthma status, nonasthmatics were more susceptible to SHS exposure than asthmatics, except for those with decreased FVC. Among asthmatics, the association of SHS exposure with decreased lung function was weaker and not significant except for maternal smoking exposure in utero $(\mathrm{aOR}=$ 7.10; 95\% CI: 1.94-25.97 for decreased FVC) and postnatal exposure $(\mathrm{aOR}=2.28 ; 95 \% \mathrm{CI}: 1.01-5.16$ for decreased FVC). For example, a significant association between SHS exposure in utero and decreased MMEF was only found in nonasthmatics ( $\mathrm{aOR}=1.31 ; 95 \% \mathrm{CI}: 1.06-1.61)$, but not in asthmatics ( $\mathrm{aOR}=1.11$; 95\% CI: 0.60-2.03). After adjustment for age, BMI, breastfeeding, parental education, home coal use, home income, and districts, we found a significant interaction between asthma status and SHS exposure for decreased lung function.

Table 3 presents the associations of SHS exposure with lung function by using a regression for continuous pulmonary function test measures, stratified by gender and asthma status. As shown in Table 3, we observed sig-

SHS and Lung Function by Gender and Asthma Status nificant associations between SHS exposure and deficit in lung function, both in males ( $\beta$-coefficients ranging from -43.10 to $-442.15 \mathrm{~mL}$ ) and females ( $\beta$-coefficients ranging from -42.53 to $-156.49 \mathrm{~mL}$ ). However, among nonasthmatics ( $\beta$-coefficients ranging from -35.23 to $-173.68 \mathrm{~mL}$ ), SHS exposure was significantly more associated with a deficit in lung function than among asthmatics.

Considering that childhood asthma may be a mediator in the relationship between perinatal SHS exposure and lung function in childhood, we further analyzed the indirect effect induced by childhood asthma (online suppl. Table S1 and S2). The results showed that 66.4 and 57.2\% of cases of in utero SHS exposure with decreased FVC and decreased FEV1, respectively, were mediated by childhood asthma.

\section{Discussion}

Few studies have investigated the adverse effects of SHS exposure on lung function in Chinese children. In this large cross-sectional study, both prenatal and postnatal SHS exposure was strongly associated with decreased lung function among Chinese children; males and nonasthmatics seem to be more susceptible than their respective counterparts.

Our findings on the effect of SHS exposure on lung function are consistent with the results of studies conducted in other countries and areas [9, 21-29], which also provided evidence of an association between SHS exposure and respiratory outcomes. For example, a study in the US, conducted by the National Health and Nutrition Examination Survey, on children 4-16 years of age identified an association between current SHS and reduced lung function, although there was a different effect for different age groups [24]. A similar study in China also found that SHS exposure during pregnancy or/and in utero, defined by urinary cotinine, had a detrimental effect on lung function among preschool children [25]. Another cohort study conducted in Norway identified that maternal smoking affected the tidal flow volume of newborns, especially girls [26]. In addition, our study also showed that the perinatal deficits from in utero exposure to maternal smoking may be larger than postnatal SHS exposure in children. For example, the aOR for decreased FVC was 6.46 (95\% CI: 2.58-16.17) in males exposed to maternal smoking during pregnancy, and the aOR was 1.39 (95\% CI: 1.07-1.81) in males for current SHS exposure. Similar to the results of our study, the 24 Cities 
Table 2. Adjusted odds ratios and $95 \%$ CIs for the prevalence of decreased lung function from environmental tobacco smoke exposure by gender and asthma status ${ }^{\text {a }}$

\begin{tabular}{|c|c|c|c|c|}
\hline \multirow[t]{2}{*}{ SHS exposure } & \multicolumn{2}{|l|}{ Gender } & \multicolumn{2}{|l|}{ Asthma } \\
\hline & males & females & yes & no \\
\hline \multicolumn{5}{|l|}{ FVC $<85 \%$ predicted } \\
\hline SHS (in utero) & $0.92(0.69-1.24)$ & $1.09(0.84-1.40)$ & $0.91(0.49-1.70)$ & $1.00(0.82-1.23)$ \\
\hline Smoking during pregnancy & $6.46(2.58-16.17)$ & $2.16(0.96-4.88)^{\mathrm{b}}$ & $7.10(1.94-25.97)$ & $2.58(1.28-5.21)$ \\
\hline SHS in first 2 years of life & $1.04(0.79-1.37)$ & $1.46(1.15-1.85)$ & $1.00(0.54-1.85)$ & $1.27(1.03-1.53)$ \\
\hline Current SHS exposure ${ }^{c}$ & $1.60(1.27-2.01)$ & $1.53(1.23-1.89)$ & $0.92(0.53-1.59)$ & $1.61(1.37-1.90)^{\mathrm{e}}$ \\
\hline Maternal smoking ${ }^{\mathrm{c}}$ & $3.08(2.12-4.47)$ & $2.21(1.56-3.15)$ & $2.28(1.01-5.16)$ & $2.51(1.91-3.29)$ \\
\hline Paternal smoking ${ }^{\mathrm{c}}$ & $1.39(1.07-1.81)$ & $1.52(1.20-1.93)$ & $0.58(0.29-1.18)$ & $1.55(1.29-1.86)^{\mathrm{e}}$ \\
\hline Other smoking ${ }^{\mathrm{c}}$ & $1.53(1.01-2.30)$ & $1.04(0.68-1.60)$ & $0.70(0.24-2.00)$ & $1.29(0.95-1.75)$ \\
\hline $1-10$ cigarettes (workday) $^{\mathrm{c}}$ & $1.62(1.27-2.05)$ & $1.44(1.15-1.80)$ & $0.80(0.44-1.45)$ & $1.58(1.33-1.87)^{\mathrm{e}}$ \\
\hline$>10$ cigarettes (workday) ${ }^{\mathrm{c}}$ & $1.59(1.06-2.38)$ & $2.12(1.49-3.03)$ & $1.55(0.67-3.57)$ & $1.89(1.42-2.50)$ \\
\hline 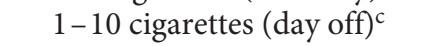 & $1.67(1.32-2.12)$ & $1.45(1.16-1.81)$ & $0.80(0.44-1.45)$ & $1.62(1.36-1.91)^{\mathrm{e}}$ \\
\hline$>10$ cigarettes $(\text { day off })^{c}$ & $1.38(0.91-2.07)$ & $1.99(1.40-2.81)$ & $1.39(0.60-3.22)$ & $1.69(1.28-2.23)$ \\
\hline \multicolumn{5}{|l|}{ FEV $1<85 \%$ predicted } \\
\hline SHS (in utero) & $1.09(0.81-1.47)$ & $0.87(0.63-1.20)$ & $0.87(0.44-1.74)$ & $0.97(0.77-1.23)$ \\
\hline Smoking during pregnancy & $4.12(1.52-11.17)$ & $1.28(0.38-4.27)$ & $1.36(0.26-7.04)$ & $2.32(1.01-5.33)$ \\
\hline SHS in first 2 years of life & $1.16(0.87-1.55)$ & $1.24(0.93-1.66)$ & $1.24(0.64-2.39)$ & $1.17(0.94-1.45)$ \\
\hline Current SHS exposure ${ }^{c}$ & $1.78(1.39-2.27)$ & $1.36(1.05-1.75)$ & $1.19(0.65-2.20)$ & $1.57(1.30-1.89)$ \\
\hline Maternal smoking ${ }^{\mathrm{c}}$ & $3.18(2.15-4.71)$ & $2.20(1.48-3.27)$ & $2.85(1.20-6.75)$ & $2.55(1.89-3.43)$ \\
\hline Paternal smoking ${ }^{\mathrm{C}}$ & $1.52(1.15-2.02)$ & $1.28(0.96-1.72)$ & $0.79(0.37-1.67)$ & $1.43(1.16-1.76)$ \\
\hline Other smoking ${ }^{\mathrm{c}}$ & $1.89(1.23-2.88)$ & $0.90(0.53-1.54)^{\mathrm{b}}$ & $0.81(0.24-2.70)$ & $1.38(0.98-1.95)$ \\
\hline $1-10$ cigarettes (workday) $^{\mathrm{c}}$ & $1.85(1.43-2.38)$ & $1.29(0.99-1.68)^{b}$ & $1.20(0.63-2.28)$ & $1.55(1.28-1.88)$ \\
\hline$>10$ cigarettes (workday) ${ }^{\mathrm{c}}$ & $1.50(0.95-2.34)$ & $1.82(1.19-2.79)$ & $1.21(0.43-3.39)$ & $1.71(1.24-2.36)$ \\
\hline 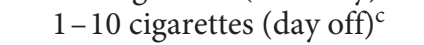 & $1.89(1.46-2.44)$ & $1.30(0.99-1.70)^{b}$ & $1.21(0.63-2.31)$ & $1.59(1.31-1.93)$ \\
\hline$>10$ cigarettes $(\text { day off })^{c}$ & $1.39(0.89-2.17)$ & $1.63(1.07-2.48)$ & $1.14(0.41-3.19)$ & $1.53(1.11-2.11)$ \\
\hline \multicolumn{5}{|l|}{$\mathrm{PEF}<75 \%$ predicted } \\
\hline SHS (in utero) & $1.23(0.85-1.77)$ & $1.05(0.77-1.43)$ & $1.01(0.46-2.21)$ & $1.11(0.87-1.43)$ \\
\hline Smoking during pregnancy & $0.87(0.11-6.66)$ & $1.83(0.63-5.33)$ & $2.83(0.55-14.41)$ & $1.12(0.34-3.69)$ \\
\hline SHS in first 2 years of life & $1.01(0.69-1.46)$ & $1.06(0.78-1.44)$ & $0.95(0.43-2.09)$ & $1.02(0.80-1.31)$ \\
\hline Current SHS exposure ${ }^{c}$ & $1.08(0.80-1.46)$ & $1.20(0.93-1.55)$ & $0.62(0.31-1.23)$ & $1.20(0.98-1.46)$ \\
\hline Maternal smoking ${ }^{\mathrm{c}}$ & $1.02(0.57-1.84)$ & $1.53(0.98-2.38)$ & $0.70(0.29-1.72)$ & $1.38(0.96-2.00)$ \\
\hline Paternal smoking ${ }^{\mathrm{C}}$ & $1.03(0.73-1.45)$ & $1.18(0.89-1.58)$ & $0.27(0.10-0.77)$ & $1.19(0.95-1.49)^{\mathrm{e}}$ \\
\hline Other smoking ${ }^{\mathrm{c}}$ & $1.49(0.89-2.48)$ & $1.11(0.69-1.79)$ & $1.74(0.66-4.58)$ & $1.16(0.80-1.69)$ \\
\hline $1-10$ cigarettes (workday) ${ }^{c}$ & $1.13(0.83-1.55)$ & $1.19(0.91-1.55)$ & $0.62(0.30-1.30)$ & $1.20(0.98-1.48)$ \\
\hline$>10$ cigarettes (workday) ${ }^{\mathrm{c}}$ & $0.87(0.47-1.59)$ & $1.33(0.83-2.12)$ & $0.62(0.17-2.31)$ & $1.17(0.80-1.72)$ \\
\hline $1-10{\text { cigarettes }(\text { day off })^{c}}^{c}$ & $1.14(0.83-1.58)$ & $1.21(0.93-1.58)$ & $0.75(0.37-1.53)$ & $1.21(0.98-1.49)$ \\
\hline$>10$ cigarettes $(\text { day off })^{\mathrm{c}}$ & $0.88(0.49-1.59)$ & $1.23(0.77-1.95)$ & $0.17(0.02-1.37)$ & $1.17(0.81-1.69)^{\mathrm{e}}$ \\
\hline \multicolumn{5}{|l|}{ MMEF $<75 \%$ predicted } \\
\hline SHS (in utero) & $1.33(0.98-1.79)$ & $1.32(1.02-1.72)$ & $1.11(0.60-2.03)$ & $1.31(1.06-1.61)$ \\
\hline Smoking during pregnancy & $0.50(0.07-3.78)$ & $2.06(0.83-5.07)$ & $-\mathrm{d}$ & $2.09(0.92-4.78)$ \\
\hline SHS in first 2 years of life & $1.13(0.84-1.52)$ & $1.20(0.92-1.56)$ & $1.18(0.65-2.16)$ & $1.13(0.91-1.39)$ \\
\hline Current SHS exposure ${ }^{c}$ & $1.45(1.13-1.85)$ & $1.33(1.06-1.67)$ & $0.92(0.53-1.59)$ & $1.41(1.18-1.68)$ \\
\hline Maternal smoking ${ }^{\mathrm{c}}$ & $1.61(1.04-2.49)$ & $1.52(1.03-2.25)$ & $0.42(0.14-1.30)$ & $1.76(1.29-2.83)^{\mathrm{e}}$ \\
\hline Paternal smoking ${ }^{\mathrm{c}}$ & $1.37(1.03-1.81)$ & $1.28(0.99-1.66)$ & $0.94(0.50-1.74)$ & $1.33(1.09-1.62)$ \\
\hline Other smoking ${ }^{\mathrm{c}}$ & $1.84(1.22-2.80)$ & $1.27(0.84-1.92)$ & $1.41(0.57-3.48)$ & $1.48(1.09-2.03)$ \\
\hline $1-10$ cigarettes (workday) $^{\mathrm{c}}$ & $1.56(1.21-2.02)$ & $1.37(1.08-1.74)$ & $0.95(0.53-1.69)$ & $1.48(1.24-1.78)$ \\
\hline$>10$ cigarettes (workday) ${ }^{\mathrm{c}}$ & $0.94(0.56-1.58)$ & $1.11(0.79-1.72)$ & $0.74(0.27-1.99)$ & $1.06(0.74-1.51)$ \\
\hline 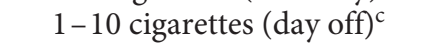 & $1.55(1.20-2.00)$ & $1.39(1.10-1.76)$ & $0.99(0.56-1.75)$ & $1.48(1.24-1.78)$ \\
\hline$>10$ cigarettes (day off) ${ }^{c}$ & $1.08(0.67-1.74)$ & $1.10(0.72-1.69)$ & $0.64(0.23-1.76)$ & $1.13(1.24-1.78)$ \\
\hline
\end{tabular}

a Adjusted for age, gender, body mass index, breastfeeding, parental education, home income, home coal use, asthma, study district. ${ }^{\mathrm{b}}$ Interaction between SHS exposure and gender: $p$ value $<0.05 .{ }^{\mathrm{c}}$ Contrast with the subjects with no current exposure to SHS. ${ }^{\mathrm{d}}$ Sample too small to detect the effect. ${ }^{e}$ Interaction between SHS exposure and asthma status: $p$ value $<0.05$. Values with $\mathrm{p} \leq 0.05$ are in bold. 
Table 3. Estimated absolute changes (standard error) in pulmonary function test due to SHS exposure by gender and asthma status ${ }^{\text {a }}$

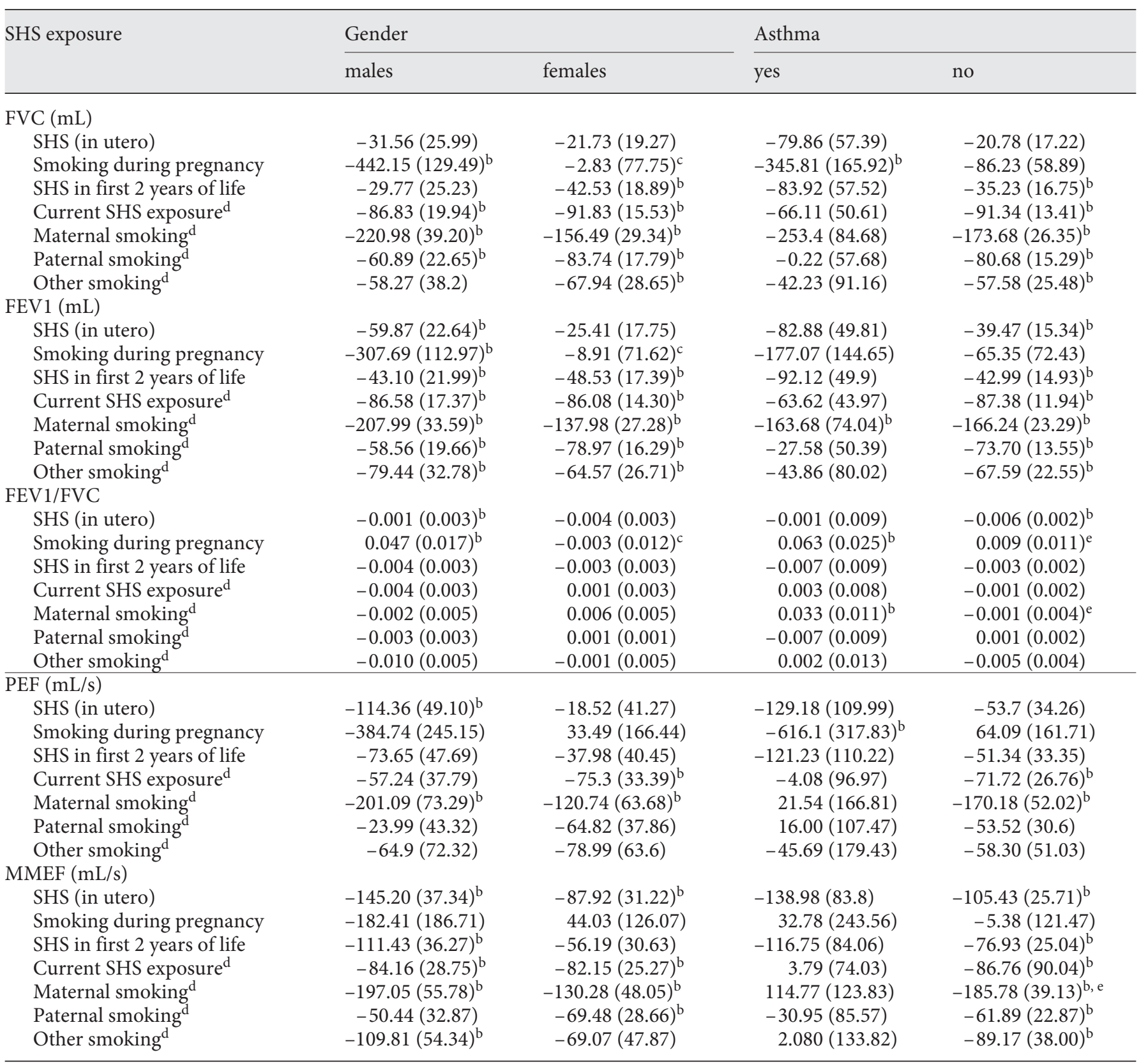

a Adjusted for age, gender, body mass index, breastfeeding, parental education, home income, home coal use, asthma, study district. ${ }^{\mathrm{b}}$ Statistically significant, at $p<0.05 .{ }^{\mathrm{c}}$ Interaction between SHS exposure and gender: $p$ value $<0.05 .{ }^{\mathrm{d}}$ Contrast with the subjects with no current exposure to SHS. ${ }^{\mathrm{e}}$ Interaction between SHS exposure and asthma status: $p$ value $<0.05$.

Study and Twelve Southern California Communities Study also reported that the effect of maternal smoking during pregnancy on measures of airway flow was greater than that of current smoking, and was not reduced by adjustment for current smoking $[8,29]$. The relative contribution to persistent deficits in lung function of in utero exposure to maternal smoking and postnatal SHS exposure is still unclear. Some scholars pointed out that differences may be due to changes in SHS exposure, such as changes in the behavior of household smokers, or the affected child may have reduced SHS exposure, which may lead to smaller estimates of effect. 
Along with these new findings, we also stratified our study population by gender and asthma status to see the detrimental effects of SHS on lung functions, which showed some statistical differences. We observed gender differences in the adverse effects of SHS exposure on lung function, with males being more vulnerable to this exposure. Consistent with our findings in children without allergic predisposition, several other studies indicate a stronger effect of intrauterine exposure on boys than on girls $[30,31]$. This is plausible because there are differences between the airways of boys and girls from early fetal lung development and throughout life [32]. For example, female lungs mature earlier with regard to surfactant production. Throughout life, females have smaller lungs than males, but their lung architecture is more advantageous with a greater airway diameter in relation to the volume of the lung parenchyma. Additionally, ovarian hormones, namely progesterone and estrogen, are also known to modify and influence the pulmonary system [33-35].

Compared with the nonasthmatics, there were few significant findings for asthmatic children, and the significant associations that were identified had a wide CI. This may be due to a small number of asthmatic children in our study $(n=460)$, especially when further categorized by exposure prevalence. For example, among children whose mother currently smoked, only 57 were asthmatic, compared to 551 children who were nonasthmatic. Although the number of asthmatic children in our study was small, our sample was still representative of northeastern China's childhood asthma prevalence and did not affect the external validity of these findings. Another possible reason for this may be related to the mediated effect induced by asthma. Childhood asthma is very likely to be a mediator in the relationship between perinatal environmental tobacco smoke exposure and lung function in childhood. SHS increases the risk of asthma, and asthma is known to increase the risk of lung function deficits. The true relationship between SHS and lung function in the asthmatic group (when stratified by childhood asthma) is hidden, as this stratification will not take into account the childhood asthma "caused" by SHS exposure. As shown in online suppl. Table S1 and S2, the relationship between in utero SHS exposure and 66.4 and $57.2 \%$ of cases with decreased FVC and FEV1, respectively, was mediated by childhood asthma. Therefore, it appears that there is a smaller association among asthmatics.

Although the data were thoroughly detailed and a large sample $(n=6,740)$ was utilized, our study had several limitations worth noting. Due to the cross-sectional nature of the data, temporality and causality could not be determined. The collection of data via a self-report also allowed for a possible recall bias of smoking behaviors. This could have potentially caused misclassification of behavioral and environmental risk factors due to the nature of the survey questions (yes/no). Mothers who may not want to admit to have smoked during pregnancy and modification of environments based on the respiratory health of their child may cause differential misclassification and underestimate the true association. Underdiagnosis of asthma may be a concern with lack of access to health care. However, this is unlikely to be an issue here because the cities used in this study were all large cities where the socioeconomic status, customs, culture, and lifestyle are similar across the population. Differences in spirometer calibration and measurement bias of readings are not expected as lung function tests were conducted by trained professionals and thus considered clinically valid. Unmeasured residual factors, such as occupation, neighborhood characteristics, and access to health care, could be potential confounders of the relationship.

In conclusion, we found that the exposure of children to SHS during pregnancy, in the postpartum period, and later in childhood was associated with decreased lung function. Maternal smoking during pregnancy and exposure to cigarette use in the household had a greater effect on respiratory outcomes of male children. China has a high population density, and the mass residential complexes built to accommodate thousands in one area may contribute to increased exposure to SHS and its potentially harmful effect on lung function. While there is a need for further research to understand the mechanisms between different environmental factors and lung function, the findings of this study demonstrate the need to implement a policy to reduce SHS and the burden of respiratory illnesses on children in China.

\section{Acknowledgments}

The authors acknowledge the cooperation of the 7 cities, school principals, teachers, and students and their parents. This research was supported by grants from the National Key Research and Development Program of China (2016YFC0207000), Major Program of National Natural Science Foundation of China (91543208), China Environmental Protection Foundation (CEPF2008-1231-5), and the Guangdong Province Natural Science Foundation (2014A050503027, 2016A030313342).

\section{Financial Disclosure and Conflicts of Interest}

The authors report no conflicts of interest. 


\section{References}

1 Lofroth G: Environmental tobacco smoke: overview of chemical composition and genotoxic components. Mutat Res 1989;222:7380.

2 Akinbami LJ, Kit BK, Simon AE: Impact of environmental tobacco smoke on children with asthma, United States, 2003-2010. Acad Pediatr 2013;13:508-516.

3 Pietinalho A, Pelkonen A, Rytilä P: Linkage between smoking and asthma. Allergy 2009; 64:1722-1727.

4 Gonzalez-Barcala FJ, Pertega S, Sampedro M, Sampedro M, Lastres JS, Gonzalez MA, Bamonde L, Garnelo L, Castro TP, ValdésCuadrado L, Carreira JM, Moure JD, Silvarrey AL: Impact of parental smoking on childhood asthma. J Pediatr (Rio J) 2013;89:294-299.

5 Quinto KB1, Kit BK, Lukacs SL, Akinbami LJ: Environmental tobacco smoke exposure in children aged 3-19 years with and without asthma in the United States, 1999-2010. NCHS Data Brief 2013;126:1-8.

6 Dong GH, Ren WH, Wang D, Yang ZH, Zhang PF, Zhao YD, He QC: Exposure to secondhand tobacco smoke enhances respiratory symptoms and responses to animals in 8,819 children in kindergarten: results from 25 districts in northeast China. Respiration 2011;81:179-185

7 Valsamis C, Krishnan S, Dozor AJ: The effects of low-level environmental tobacco smoke exposure on pulmonary function tests in preschool children with asthma. J Asthma 2014; 51:685-690.

8 Li YF, Gilliland FD, Berhane K, McConnell R, Gauderman WJ, Rappaport EB, Peters JM: Effects of in utero and environmental tobacco smoke exposure on lung function in boys and girls with and without asthma. Am J Respir Crit Care Med 2000;162:2097-2104.

9 Gilliland FD, Berhane K, McConnell R, Gauderman WJ, Vora H, Rappaport EB, Avol E, Peters JM: Maternal smoking during pregnancy, environmental tobacco smoke exposure and childhood lung function. Thorax 2000;55:271-276.

10 Wang L, Pinkerton KE: Detrimental effects of tobacco smoke exposure during development on postnatal lung function and asthma. Birth Defects Res C Embryo Today 2008;84:54-60.

11 Sherrill DL, Martinez FD, Lebowitz MD, Holdaway MD, Flannery EM, Herbison GP, Stanton WR, Silva PA, Sears MR: Longitudinal effects of passive smoking on pulmonary function in New Zealand children. Am Rev Respir Dis 1992;145:1136-1141.

12 Dijkstra L, Houthuijs D, Brunekreef B, Akkerman I, Boleij JS: Respiratory health effects of the indoor environment in a population of Dutch children. Am Rev Respir Dis 1990;142: 1172-1178.
13 US Environmental Protection Agency: Respiratory Health Effects of Passive Smoking: Lung Cancer and Other Disorders. Washington, US Environmental Protection Agency, 1992.

14 Ulrik CS: Outcome of asthma: longitudinal changes in lung function. Eur Respir J 1999; 13:904-918.

15 Peters JM, Avol E, Gauderman WJ, Linn WS, Navidi W, London SJ, Margolis H, Rappaport E, Vora H, Gong H Jr, Thomas DC: A study of twelve Southern California communities with differing levels and types of air pollution. II. Effects on pulmonary function. Am J Respir Crit Care Med 1999;159:768-775.

16 Svanes C, Omenaas E, Jarvis D, Gulsvik A, Burney P: Parental smoking in childhood and adult obstructive lung disease: results from the European Community Respiratory Health Survey. Thorax 2004;59:295-302.

17 Tong VT, Jones JR, Dietz PM, D’Angelo D, Bombard JM; Centers for Disease Control and Prevention (CDC): Trends in smoking before, during, and after pregnancy - Pregnancy Risk Assessment Monitoring System (PRAMS), United States, 31 sites, 2000-2005. MMWR Surveill Summ 2009;58:1-29.

18 Yang GH, Ma JM, Liu N, Zhou LN: Smoking and passive smoking in Chinese, 2002. Zhonghua Liu Xing Bing Xue Za Zhi 2005;26:7783.

19 Zeng XW, Vivian E, Mohammed KA, Jakhar S, Vaughn M, Huang J, Zelicoff A, Xaverius P, Bai Z, Lin S, Hao YT, Paul G, Morawska L, Wang SQ, Qian Z, Dong GH: Long-term ambient air pollution and lung function impairment in Chinese children from a high air pollution range area: The Seven Northeastern Cities (SNEC) Study. Atmos Environ 2016; 138:144-151.

20 Ma YN, Wang J, Dong GH, Liu MM, Wang D, Liu YQ, Zhao Y, Ren WH, Lee YL, Zhao YD, He QC: Predictive equations using regression analysis of pulmonary function for healthy children in Northeast China. PLoS One 2013;8:e63875.

21 Tsai CH, Huang JH, Hwang BF, Lee YL: Household environmental tobacco smoke and risks of asthma, wheeze and bronchitic symptoms among children in Taiwan. Respir Res 2010;11:11.

22 Henderson AJ, Newson RB, Rose-Zerilli M, Ring SM, Holloway JW, Shaheen SO: Maternal Nrf2 and gluthathione-S-transferase polymorphisms do not modify associations of prenatal tobacco smoke exposure with asthma and lung function in school-aged children. Thorax 2010;65:897-902.
23 Quinto KB, Kit BK, Lukacs SL, Akinbami LJ: Environmental tobacco smoke exposure in children aged 3-19 years with and without asthma in the United States, 1999-2010. NCHS Data Brief 2013;126:1-8.

24 Mannino DM, Moorman JE, Kingsley B, Rose $D$, Repace J: Health effects related to environmental tobacco smoke exposure in children in the United States: data from the Third National Health and Nutrition Examination Survey. Arch Pediatr Adolesc Med 2001;155: 36-41.

25 Leung TF, Chan IH, Liu TC, Lam CW, Wong GW: Relationship between passive smoking exposure and urinary heavy metals and lung functions in preschool children. Pediatr Pulmonol 2013;48:1089-1097.

26 Lodrup Carlsen KC, Jaakkola JJ, Nafstad P, Carlsen $\mathrm{KH}$ : In utero exposure to cigarette smoking influences lung function at birth. Eur Respir J 1997;10:1774-1779.

27 Beyer D, Mitfessel H, Gillissen A: Maternal smoking promotes chronic obstructive lung disease in the offspring as adults. Eur J Med Res 2009;14:27-31.

28 Gergen PJ, Fowler JA, Maurer KR, Davis WW, Overpeck MD: The burden of environmental tobacco smoke exposure on the respiratory health of children 2 months through 5 years of age in the United States: Third National Health and Nutrition Examination Survey, 1988 to 1994. Pediatrics 1998;101:E8.

29 Cunningham J, Dockery DW, Speizer FE: Maternal smoking during pregnancy as a predictor of lung function in children. Am J Epidemiol 1994;139:1139-1152.

30 Cunningham J, Dockery DW, Gold DR, Speizer FE: Racial differences in the association between maternal smoking during pregnancy and lung function in children. Am J Respir Crit Care Med 1995; 152:565-569.

31 Hayatbakhsh MR, Sadasivam S, Mamun AA, Najman JM, Williams GM, O'Callaghan MJ: Maternal smoking during and after pregnancy and lung function in early adulthood: a prospective study. Thorax 2009;64:810-814.

32 Becklake MR, Kauffmann F: Gender differences in airway behaviour over the human life span. Thorax 1999;54:1119-1138.

33 Mathai SC, Hassoun PM, Puhan MA, Zhou $\mathrm{Y}, \mathrm{Wise}$ RA: Sex differences in response to tadalafil in pulmonary arterial hypertension. Chest 2015;147:188-197.

34 Franco RL, Bowen MK, Arena R, Privett SH, Acevedo EO, Wickham EP, Evans RK: Sex differences in pulmonary oxygen uptake kinetics in obese adolescents. J Pediatr 2014; 165:1161-1165.

35 Harms CA, Rosenkranz S: Sex differences in pulmonary function during exercise. Med Sci Sports Exerc 2008;40:664-668. 